CLINICAL STUDY

\title{
Effects of medical therapies for acromegaly on glucose metabolism
}

\author{
C Urbani, C Sardella, A Calevro, G Rossi ${ }^{1}$, I Scattina, M Lombardi, I Lupi, L Manetti, E Martino and F Bogazzi \\ Department of Endocrinology and Metabolism, University of Pisa, Ospedale Cisanello, Via Paradisa 2, 56124 Pisa, Italy and ${ }^{1}$ National Research Council, \\ Unit of Biostatistics and Epidemiology, Pisa, Italy
}

(Correspondence should be addressed to F Bogazzi; Email: fbogazzi@hotmail.com)

\begin{abstract}
Objective: Abnormalities of glucose metabolism are common findings of acromegaly. However, robust evidence on whether therapy with somatostatin analogs (SSAs) or pegvisomant (PEG) differently affects glucose metabolism is lacking. The purpose of this study was to evaluate the effects of therapy with SSAs, PEG, or their combination on glucose metabolism in a large series of acromegalic patients. Design: This was a historical-prospective study. Among 50 consecutive acromegalic patients under SSA therapy, acromegaly in 19 patients was controlled. PEG used in combination with SSA therapy allowed the control of acromegaly in the remaining 31 patients and was then continued as monotherapy in 18 patients.

Methods: The following parameters were evaluated at the diagnosis of acromegaly and during different treatments: fasting plasma glucose (FPG) and insulin concentrations, insulin sensitivity (QUICK-I), homeostasis model assessment of insulin resistance (HOMA2-IR), and plasma glucose and insulin concentrations during the oral glucose tolerance test (OGTT). Comparison was made using analysis for paired data.

Results: Insulin resistance improved when acromegaly was controlled with therapy with SSAs, PEG, or SSA + PEG. However, FPG concentrations were higher during SSA therapy (alone or combined with PEG) than at the diagnosis of acromegaly, even when corrected for disease activity, whereas they were reduced during PEG therapy. Mean glucose concentrations during the OGTT were higher in patients receiving SSA therapy than in those receiving PEG therapy. In addition, the prevalence of diabetes or impaired glucose tolerance was higher during SSA therapy than at diagnosis or during PEG therapy and was not influenced by disease control.

Conclusions: Medical therapies for acromegaly reduce insulin resistance and increase insulin sensitivity; on the contrary, glucose indexes may be differently affected by SSA or PEG therapy.
\end{abstract}

European Journal of Endocrinology 169 99-108

\section{Introduction}

Acromegaly is characterized by an unconstrained secretion of GH and IGF1, which have opposite effects on glucose metabolism (1). Impaired glucose tolerance (IGT) and overt type 2 diabetes mellitus (DM) are frequent findings in acromegalic patients, with a prevalence of the latter ranging from 19 to $56 \%(2,3,4,5)$.

The mechanisms that underlie the abnormalities of glucose metabolism in acromegaly are not completely understood. However, GH reduces glucose uptake and oxidation in the muscle, increases hepatic gluconeogenesis, and directly induces a condition of insulin resistance through the activation of intracellular lipolysis and lipid oxidation $(1,2,6,7)$.

Although transsphenoidal pituitary adenomectomy remains the first-line treatment for most patients with acromegaly, medical therapies with long-acting somatostatin analogs (SSAs) or the GH-receptor antagonist (pegvisomant, PEG) have become increasingly relevant, either for the treatment of residual disease after neurosurgery (3) or as primary therapy in those patients in whom pituitary surgery is not feasible or contraindicated (8).

The impact of SSA therapy on glucose homeostasis in acromegaly is complex and, somehow, unpredictable due to the concomitant inhibition of the secretion of insulin and $\mathrm{GH}$, which have opposite effects on glucose metabolism $(9,10,11,12,13)$. A recent meta-analysis revealed that SSA therapy did not significantly change the levels of fasting glucose and $\mathrm{HbAlc}$, whereas it reduced fasting insulin concentrations (14). However, results of single studies included in that meta-analysis are divergent, suggesting that SSA therapy may have a more profound impact on glucose metabolism in a subset of patients (14).

PEG therapy has been reported to lower fasting blood glucose levels $(15,16,17,18,19,20)$ and to improve 
glucose tolerance in acromegalic patients $(16,17,18,19)$. However, the effect of PEG therapy on insulin sensitivity remains unclear since only a few studies, enrolling a limited number of subjects, have reported an improvement of glucose tolerance, likely due to a decrease in peripheral insulin resistance $(18,19,20,21)$.

The purpose of this historical-prospective study was to evaluate, in a cohort of acromegalic patients, whether therapy with SSAs, SSAs combined with PEG (SSA + PEG), or PEG alone differently affects insulin or glucose metabolism.

\section{Subjects and methods}

\section{Subjects}

Data were collected from clinical records of 62 consecutive acromegalic patients referred to our Department from December 2006 to December 2010, treated with SSAs, and eligible for the study. Eligible patients were those with the first diagnosis of acromegaly or those with persistent disease after pituitary adenomectomy.

Patients with DM $(n=5)$ or IGT $(n=25)$ treated with diet therapy and not taking insulin or oral hypoglycemic agents were included in the study. Twelve patients, either receiving therapies for DM or with abnormal hepatic or renal function, were excluded. Hence, 50 of the 62 patients with active acromegaly were included in this study. Thirty-one subjects were those with the first diagnosis of acromegaly, whereas 19 patients had persistent disease after pituitary adenomectomy.

Clinical and biochemical findings of the patients are summarized in Table 1. Diagnosis of active acromegaly was established on the basis of clinical and biochemical criteria as reported previously (22). Acromegaly was defined controlled when the IGF1 index (the ratio of the observed serum IGF1 concentration to the upper normal limit for the age) was $\leq 1$ during therapy with SSAs, PEG, or a combination of the two drugs as reported previously (23).

As shown in Tables 1 and 2, ten patients had at least one pituitary hormone deficit that was appropriately corrected with hormone replacement therapy before the baseline evaluation of glucose metabolism was performed. In particular, eight patients received $\mathrm{L}-\mathrm{T}_{4}$ therapy, three patients received hydrocortisone therapy, five male patients received testosterone therapy, and two women received estrogen-progestin therapy.

\section{Study design}

This was a historical-prospective study, approved by the Internal Review Board of our Department. The design of the study is shown in Fig. 1. Although the study was retrospective in nature, all patients were followed on the basis of a standardized protocol, adopted by our
Table 1 Clinical and biochemical findings of the patients $(n=50)$ at the diagnosis of acromegaly. Qualitative data are expressed as the number and percentage of total; quantitative data are expressed as mean \pm S.E.M.

\begin{tabular}{lc}
\hline & Value \\
\hline Age (years) & $47.81 \pm 1.76$ \\
Female & $27(54.0)$ \\
BMI $\left(\mathrm{kg} / \mathrm{m}^{2}\right)$ & $28.41 \pm 0.61$ \\
Macroadenoma & $32(64.0)$ \\
Estimated delay in diagnosis (months) & $107.47 \pm 11.24$ \\
Hypopituitarism & $10(20.0)$ \\
Hypogonadism & $1(2.0)$ \\
Hypogonadism+hypothyroidism & $4(8.0)$ \\
Hypoadrenalism & $1(2.0)$ \\
Hypothyroidism & $2(4.0)$ \\
Total hypopituitarism & $2(4.0)$ \\
GH ( $\mu$ g/l) & $12.16 \pm 2.13$ \\
IGF1 index & $2.80 \pm 0.17$ \\
Pituitary adenomectomy & $19(38.0)$ \\
Glucose tolerance status & \\
NGT & $22(44.0)$ \\
IFG & $3(6.0)$ \\
IGT & $18(36.0)$ \\
IFG + IGT & $2(4.0)$ \\
Type 2 DM & $5(10.0)$ \\
\hline
\end{tabular}

IGF1 index, the ratio of the measured IGF1 value to the upper limit for age NGT, normal glucose tolerance; IFG, impaired fasting glucose; IGT, impaired glucose tolerance; DM, diabetes mellitus.

Department for several years, meaning that data were prospectively collected.

Clinical and biochemical evaluation of the acromegalic patients was performed every 6 months and therapy for acromegaly was modified as appropriate during each visit.

It is our practice to evaluate glucose metabolism at the diagnosis of acromegaly and during the follow-up period, as detailed below.

SSA therapy is usually proposed as a first-line medical therapy and dose is titrated every 6 months up to $30 \mathrm{mg}$ octreotide LAR or up to $120 \mathrm{mg}$ lanreotide Autogel every 28 days. If acromegaly in the patient is still uncontrolled under a maximal SSA dose, PEG is added at the starting dose of $10 \mathrm{mg} /$ day, and dosage is adjusted until biochemical control of acromegaly is achieved (SSA+PEG), usually within 3-6 months. It is our practice to stop SSA therapy and to continue PEG therapy alone when control of acromegaly is achieved.

For the purpose of the study, the following groups of patients were considered (Fig. 1): patients with active acromegaly not treated with SSAs or PEG $(n=50)$; patients with uncontrolled acromegaly treated with a maximal dose of SSAs for at least 6 months $(n=31)$; patients with controlled acromegaly under SSA therapy $(n=19)$; patients with controlled acromegaly under SSA + PEG therapy $(n=31)$; and patients with controlled acromegaly under PEG therapy $(n=18)$. When the present study was completed, 13 patients were still under the combined therapy.

A similar number of patients received octreotide LAR therapy $(n=26)$ and lanreotide Autogel therapy $(n=24)$. 
Table 2 Comparison of basal findings of patients with controlled disease $\left(\mathrm{SSA}_{\text {contr }}\right)$ or uncontrolled disease $\left(S_{S A} A_{\text {un-contr }}\right)$ during SSA therapy. Quantitative data were compared as means \pm S.E.M. and qualitative data as numbers and percentages.

\begin{tabular}{|c|c|c|c|}
\hline & \multicolumn{2}{|c|}{ Basal evaluation } & \multirow[b]{2}{*}{$P$} \\
\hline & $\mathrm{SSA}_{\text {contr }}$ & $\mathrm{SSA}_{\text {un-contr }}$ & \\
\hline Age (years) & $50.83 \pm 2.62$ & $46.47 \pm 2.33$ & 0.2212 \\
\hline Female & $11(57.9)$ & $16(\overline{51.6)}$ & 0.6649 \\
\hline $\mathrm{BMI}\left(\mathrm{kg} / \mathrm{m}^{2}\right)$ & $28.39 \pm 1.00$ & $28.45 \pm 0.81$ & 0.9626 \\
\hline Macroadenoma & $10(52.6)$ & $22(70.9)$ & 0.1918 \\
\hline Estimated delay in diagnosis (months) & $101.4 \pm 11.24$ & $118.0 \pm 25.41$ & 0.4813 \\
\hline Pituitary adenomectomy & $6(31.6)$ & $13(41.9)$ & 0.4614 \\
\hline $\mathrm{GH}(\mu \mathrm{g} / \mathrm{l})$ & $15.24 \pm 4.77$ & $10.04 \pm 2.05$ & 0.3282 \\
\hline IGF1 index & $2.85 \pm 0.34$ & $2.78 \pm 0.19$ & 0.7667 \\
\hline Fasting glucose $(\mathrm{mg} / \mathrm{dl})$ & $93.89 \pm 3.01$ & $92.50 \pm 1.66$ & 0.6892 \\
\hline Fasting insulin $(\mu \mathrm{U} / \mathrm{ml})$ & $11.21 \pm 2.77$ & $15.41 \pm 2.95$ & 0.3053 \\
\hline $\mathrm{HbA} 1 \mathrm{c}(\%)$ & $6.04 \pm 0.16$ & $6.29 \pm 0.14$ & 0.2656 \\
\hline HOMA2-IR & $1.42 \pm 0.34$ & $1.93 \pm 0.35$ & 0.3002 \\
\hline HOMA- $\beta$ & $107.87 \pm 17.23$ & $135.44 \pm 17.17$ & 0.2644 \\
\hline Disposition index & $88.40 \pm 7.33$ & $87.89 \pm 6.49$ & 0.9586 \\
\hline QUICK index & $0.345 \pm 0.008$ & $0.339 \pm 0.008$ & 0.6207 \\
\hline OGTT glucose at $0 \mathrm{~min}(\mathrm{mg} / \mathrm{dl})$ & $87.22 \pm 3.93$ & $93.80 \pm 2.14$ & 0.1531 \\
\hline OGTT glucose at $120 \mathrm{~min}(\mathrm{mg} / \mathrm{dl})$ & $151.83 \pm 9.94$ & $132.53 \pm 8.92$ & 0.1563 \\
\hline OGTT AUC ${ }_{\text {glu }}(\mathrm{mg} / \mathrm{dl} \times 120 \mathrm{~min})$ & $19093 \pm 962$ & $17530 \pm 698$ & 0.1974 \\
\hline OGTT AUC ins $(\mu \mathrm{U} / \mathrm{ml} \times 120 \mathrm{~min})$ & $7561 \pm 1454$ & $9330 \pm 1074$ & 0.3372 \\
\hline $\mathrm{AUC}_{\text {ins }} / \mathrm{AUC} \mathrm{C}_{\mathrm{glu}}$ & $0.40 \pm 0.06$ & $0.55 \pm 0.07$ & 0.1179 \\
\hline Matsuda index (ISI) & $4.69 \pm 0.48$ & $3.75 \pm 0.45$ & 0.1656 \\
\hline Insulinogenic index & $0.62 \pm 0.14$ & $0.97 \pm 0.23$ & 0.2008 \\
\hline \multicolumn{4}{|l|}{ Glucose tolerance status } \\
\hline NGT & $5(26.3)$ & $17(54.8)$ & 0.0453 \\
\hline IFG & $2(10.5)$ & $1(3.2)$ & 0.2999 \\
\hline IGT & $10(52.6)$ & $8(25.8)$ & 0.0560 \\
\hline $\mathrm{IFG}+\mathrm{IGT}$ & $1(5.3)$ & $1(3.2)$ & 0.7250 \\
\hline Type 2 DM & $1(5.3)$ & $4(12.9)$ & 0.3619 \\
\hline Hypopituitarism & $4(21.1)$ & $6(19.4)$ & 0.8845 \\
\hline Hypogonadism & $1(5.3)$ & $0(0.0)$ & 0.1606 \\
\hline Hypogonadism + hypothyroidism & $1(5.3)$ & $3(9.7)$ & 0.5659 \\
\hline Hypoadrenalism & $1(5.3)$ & $0(0.0)$ & 0.1606 \\
\hline Hypothyroidism & $1(5.3)$ & $1(3.2)$ & 0.7250 \\
\hline Total hypopituitarism & $0(0.0)$ & $2(6.5)$ & 0.1612 \\
\hline
\end{tabular}

IGF1 index, the ratio of the measured IGF1 value to the upper limit for age; $A U C_{\text {glu }}$, area under the OGTT curve for glucose; $A U C_{\text {ins }}$, area under the OGTT curve for insulin; $A \cup C_{\text {ins }} / A \cup C_{\text {glu, }}$, the ratio between the two AUC; NGT, normal glucose tolerance; IFG, impaired fasting glucose; IGT, impaired glucose tolerance; DM, diabetes mellitus.

Among patients treated with octreotide LAR, acromegaly was controlled in 10 patients (mean dose \pm s.E.M. $25 \pm 1.7 \mathrm{mg}$ ) and uncontrolled in 16 patients (mean dose \pm s.e.м. $28.8 \pm 0.9 \mathrm{mg}, P=0.0372$ vs controlled). Among patients treated with lanreotide Autogel, acromegaly was controlled in 9 patients (mean dose \pm s.e.M. $120 \pm 0 \mathrm{mg}$ ) and uncontrolled in 15 patients (mean dose \pm s.e.m. $120 \pm 0 \mathrm{mg}, P=1$ vs controlled). During the combined therapy, 16 patients received octreotide LAR therapy (mean dose \pm s.E.M. $27.50 \pm 1.12 \mathrm{mg}$ ) and 15 patients received lanreotide Autogel therapy (mean dose \pm s.e.m. $120 \pm 0 \mathrm{mg}$ ).

It is interesting to underscore that the mean daily dose of PEG did not statistically differ when the same patients received the drug in combination with SSAs or alone (SSA + PEG, mean dose \pm s.E.M., $16.9 \pm 1.7 \mathrm{mg} /$ day; PEG alone, mean dose \pm s.e.m., $18.9 \pm 1.7 \mathrm{mg} /$ day; $P=0.3101)$.

After the baseline evaluation, glucose metabolism was assessed, on average, 12 months after starting SSA therapy and at least 6 months after any change in the therapeutic regimen.

\section{Evaluation of fasting glucose metabolism}

Glucose metabolism was assessed by measuring fasting plasma glucose (FPG), fasting serum insulin, and HbA1c concentrations. In addition, glucose and insulin concentrations were evaluated during a standard 2-h oral glucose tolerance test (OGTT, $75 \mathrm{~g}$ glucose), with glucose and insulin samples being obtained every $30 \mathrm{~min}$. Subjects with an increased risk for diabetes (IGT, impaired fasting glucose (IFG), and $\mathrm{HbA1c}$ comprised between 5.7 and $6.4 \%$ ) or diagnosed as having DM were identified according to the recommendations of the American Diabetes Association (24).

Basal insulin resistance was evaluated using the homeostasis model assessment of insulin resistance (HOMA2-IR) index, which correlates with estimates obtained by the use of the euglycemic clamp $(25,26)$. 


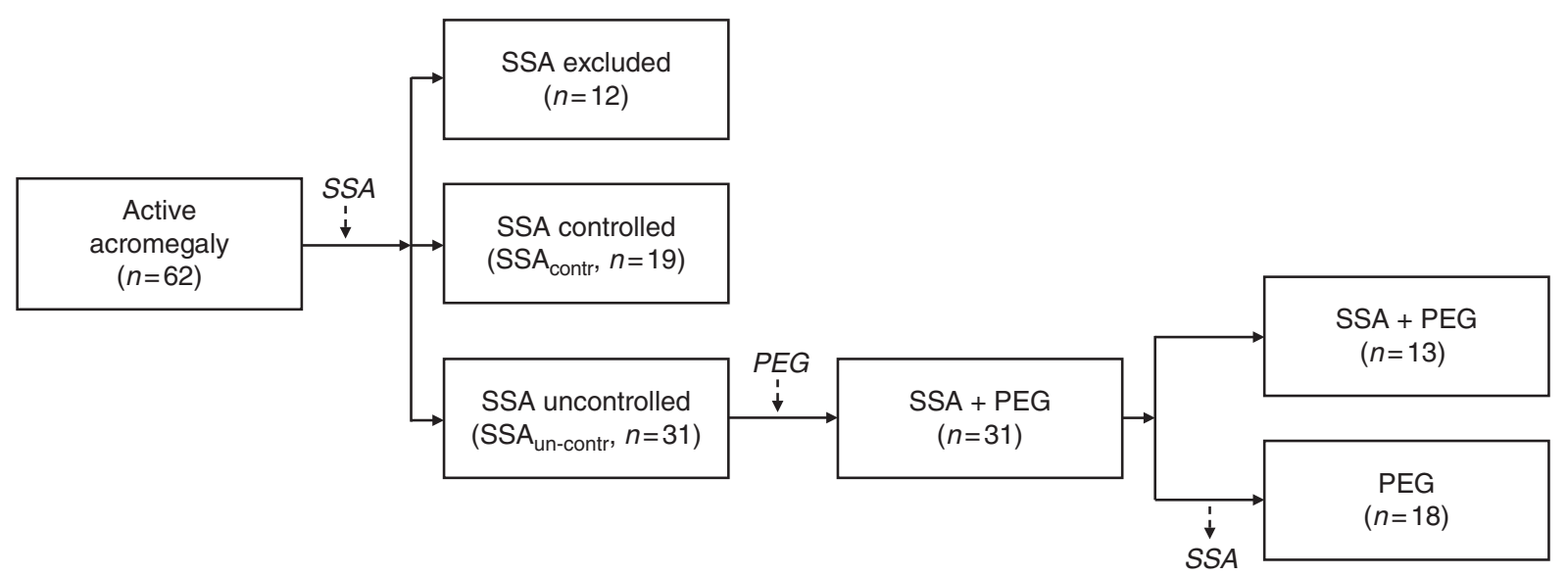

Figure 1 Study design. Clinical records of 62 consecutive patients on somatostatin analog (SSA) therapy were analyzed. Twelve patients were not eligible for the study (see Materials and methods). The remaining 50 patients on SSA therapy were stratified by acromegaly control. Those with uncontrolled disease $\left(S S A_{u n-c o n t r}\right)$ received pegvisomant (PEG) in addition to SSA therapy (SSA + PEG). After achievement of disease control, SSA therapy was withdrawn and PEG therapy was continued in a subset of patients (PEG). Thirteen patients were still under the combined therapy when the present study was performed. This subset of patients was not investigated further. Number refers to the number of patients.

$\beta$-Cell function was assessed using the homeostasis model of deficient $\beta$-cell function (HOMA- $\beta$ ), which has been validated with the clamp-derived measures of $\beta$-cell function and with the estimate from the intravenous glucose tolerance test (25).

HOMA2-IR and HOMA- $\beta$ were calculated using the computer HOMA-2 calculator version 2.2 (http://www. dtu.ox.ac.uk/homacalculator/index.php).

A simplified version of the disposition index (DI) was calculated as the ratio of HOMA- $\beta$ to HOMA2-IR, as described previously (27).

Insulin sensitivity was expressed by the QUICK index (QUICK-I), calculated as described previously (28), and by the Insulin sensitivity index (ISI, or Matsuda Index), a composite index derived from the OGTT results (29).

\section{OGTT area under the curve}

The areas under the curve of glucose $\left(\mathrm{AUC}_{\mathrm{glu}}\right)$ and insulin $\left(\mathrm{AUC}_{\mathrm{ins}}\right)$ during the 2-h OGTT were calculated according to the 'trapezoidal approach' as described by Tai (30). The $\mathrm{AUC}_{\text {ins/glu }}$ ratio, which is an indicator of insulin secretion, was also calculated (31).

In order to evaluate early insulin secretion, in response to glucose load, we utilized the insulinogenic index, calculated as follows: (Ins30-Ins0)/(glu30-Glu0) (32).

\section{Assays}

Serum GH concentrations were measured using a chemiluminescence immunoassay (Liaison hGH, Diasorin, SpA, Saluggia, Italy), calibrated against the IS 98/574. The sensitivity of this GH assay was $0.05 \mu \mathrm{g} / \mathrm{l}$; the intra- and inter-assay coefficients of variation were 4.1 and $7.3 \%$ respectively. Normal values for GH concentrations in our laboratory range from 0.05 to $5 \mu \mathrm{g} / \mathrm{l}$. Serum IGF1 concentrations were measured using an automated RIA (DIAsource ImmunoAssays S.A., Nivelles, Belgium), which included ethanol/acid extraction. Normal values in our laboratory, derived from a previous study performed in over 800 healthy subjects, are as follows: 151-504 $\mu \mathrm{g} / \mathrm{l}, 20-29$ years; 120-383 $\mu \mathrm{g} / \mathrm{l}, \quad 30-39$ years; $101-314 \mu \mathrm{g} / \mathrm{l}, 40-49$ years; $88-269 \mu \mathrm{g} / \mathrm{l}, \quad 50-59$ years; $78-237 \mu \mathrm{g} / \mathrm{l}$, 60-69 years; and 70-212 $\mu \mathrm{g} / \mathrm{l}, 70-79$ years (33). To compare IGF1 values in the different groups of age, we adopted the IGF1 index (the ratio of the IGF1 value measured the upper limit of the normal range for age) as reported previously (23).

Serum insulin concentrations were measured using an IRMA (DIAsource ImmunoAssays S.A.). The sensitivity of the assay was $1.0 \mu \mathrm{IU} / \mathrm{ml}$; the intraand inter-assay coefficients of variation were 2.1 and $6.5 \%$ for low insulin concentrations $(6-14 \mu \mathrm{IU} / \mathrm{ml})$ and 1.5 and $6.1 \%$ for higher insulin concentrations (53-200 $\mu \mathrm{IU} / \mathrm{ml})$.

Plasma glucose and $\mathrm{HbAlc}$ concentrations were analyzed using standard commercial assays. In our laboratory, normal values for FPG concentrations range from 74 to $100 \mathrm{mg} / \mathrm{dl}$, whereas $\mathrm{HbAlc} \%$ values $<5.7 \%$ are considered normal.

Pituitary magnetic resonance imaging was performed at the diagnosis of acromegaly and annually thereafter.

\section{Statistical analysis}

Quantitative data are expressed as mean \pm s.E.M. and qualitative data as percentage. The difference between patients with controlled and uncontrolled disease under SSA therapy regarding basal values was evaluated by 
Table 3 Basal values for the evaluation of metabolic parameters during different therapies for acromegaly. Values are expressed as mean \pm S.E.M.

\begin{tabular}{|c|c|c|c|}
\hline & $\begin{array}{c}\text { Basal values for } \\
\text { SSA therapy }(n=50)\end{array}$ & $\begin{array}{c}\text { Basal values for } \\
\text { SSA+PEG therapy }(n=31)\end{array}$ & $\begin{array}{l}\text { Basal evaluation for } \\
\text { PEG therapy }(n=18)\end{array}$ \\
\hline $\mathrm{GH}(\mu \mathrm{g} / \mathrm{l})$ & $12.15 \pm 14.79$ & $3.84 \pm 5.04$ & $32.70 \pm 21.47$ \\
\hline IGF1 index & $2.80 \pm 1.19$ & $2.04 \pm 0.55$ & $0.68 \pm 0.21$ \\
\hline Fasting glucose (mg/dl) & $92.90 \pm 10.44$ & $106.41 \pm 13.45$ & $97.16 \pm 15.68$ \\
\hline Fasting insulin $(\mu \mathrm{U} / \mathrm{ml})$ & $13.84 \pm 11.7$ & $12.73 \pm 10.63$ & $5.89 \pm 2.80$ \\
\hline $\mathrm{HbA1c}(\%)$ & $6.14 \pm 0.47$ & $6.41 \pm 0.49$ & $5.93 \pm 0.55$ \\
\hline HOMA2-IR & $1.74 \pm 1.64$ & $1.64 \pm 1.75$ & $0.78 \pm 0.56$ \\
\hline HOMA- $\beta$ (\%) & $125.69 \pm 81.14$ & $87.19 \pm 52.50$ & $68.12 \pm 17.77$ \\
\hline Disposition index & $88.18 \pm 31.18$ & $66.65 \pm 22.56$ & $107.82 \pm 46.44$ \\
\hline QUICK index & $0.34 \pm 0.04$ & $0.34 \pm 0.03$ & $0.37 \pm 0.03$ \\
\hline OGTT glucose at $0 \mathrm{~min}(\mathrm{mg} / \mathrm{dl})$ & $91.16 \pm 13.90$ & $103.09 \pm 12.00$ & $98.55 \pm 18.61$ \\
\hline OGTT glucose at $120 \mathrm{~min}(\mathrm{mg} / \mathrm{dl})$ & $140.29 \pm 46.62$ & $164.91 \pm 57.15$ & $144.45 \pm 49.05$ \\
\hline OGTT AUC $\mathrm{glu}(\mathrm{mg} / \mathrm{dl} \times 120 \mathrm{~min})$ & $18177.2 \pm 3934.0$ & $19197.3 \pm 4025.0$ & $18345.0 \pm 3145.7$ \\
\hline OGTT AUC ${ }_{\text {ins }}(\mu \mathrm{U} / \mathrm{ml} \times 120 \mathrm{~min})$ & $8767.60 \pm 5262.37$ & $3564.38 \pm 2175.86$ & $2971.85 \pm 1851.55$ \\
\hline$A \cup C_{\text {ins }} / A \cup C_{\text {glu }}$ & $0.50 \pm 0.31$ & $0.19 \pm 0.11$ & $0.16 \pm 0.09$ \\
\hline Matsuda index & $4.05 \pm 2.10$ & $6.51 \pm 1.76$ & $7.84 \pm 2.77$ \\
\hline Insulinogenic index & $0.85 \pm 0.98$ & $0.17 \pm 0.16$ & $0.16 \pm 0.15$ \\
\hline
\end{tabular}

IGF1 index, the ratio of the measured IGF1 value to the upper limit for age; AUC $_{\text {glu }}$, area under the OGTT curve for glucose; $A U C_{\text {ins, }}$ area under the OGTT curve for insulin.

ANOVA. Quantitative paired data were analyzed by ANOVA for repeated measures to evaluate differences between basal and somatostatin therapy and between different therapeutic groups. The comparison between patients with controlled and uncontrolled disease under SSA therapy for the difference between basal values and values observed under therapy was made by ANOVA. Likewise, the following comparisons, SSA controlled vs SSA + PEG, SSA controlled vs PEG, and SSA + PEG vs PEG, for the difference between basal values and values observed under therapy were made by ANOVA. The difference in the proportion of abnormalities of glucose metabolism between baseline and during therapy was evaluated by the exact McNemar test.

A two-sided $P$ value $<0.05$ was considered to be statistically significant. Statistical analysis was performed using the SPSS 13.0 (SPSS, Inc.) software and StatXact 4 (Cytel Co., Cambridge, MA, USA).

\section{Results}

\section{Demographic and general considerations}

The evaluation of glucose metabolism encompassed the study period from December 2006 to December 2010; changes in various parameters during different therapies for acromegaly were evaluated using paired data analysis, reflecting changes in the same patient. Changes in glucose and insulin metabolism parameters were expressed as delta $(\Delta)$ values, taking into account the baseline values of each therapy (Table 3). During the study period, BMI did not change significantly (mean BMI \pm s.e.M.: diagnosis, $28.41 \pm 0.61 \mathrm{~kg} / \mathrm{m}^{2}$; $\mathrm{SSA}_{\text {all }}$, $29.76 \pm 1.05 \mathrm{~kg} / \mathrm{m}^{2} ;$ SSA + PEG, $29.46 \pm 1.57 \mathrm{~kg} / \mathrm{m}^{2}$; and PEG $\left.29.45 \pm 1.25 \mathrm{~kg} / \mathrm{m}^{2} ; P=0.8734\right)$.

\section{Glucose metabolism during the fasting state}

FPG levels differed significantly among the study groups (Tables 4, 5, and 6). FPG concentrations were higher during SSA therapy than at the diagnosis of acromegaly $\left(\Delta S S A_{\text {all }}\right.$ - basal: $\left.10.45 \pm 1.47, P<0.001\right)$, mainly in patients with uncontrolled disease $\left(\Delta S S A_{\text {contr }}\right.$ - basal vs $\Delta S_{S A} A_{\text {un-contr }}$ - basal $\left.P=0.0093\right)$. In patients with controlled disease, FPG levels were lower during the combined therapy (SSA + PEG) than during therapy with SSAs alone and further decreased when SSA therapy was withdrawn and only PEG therapy was continued (Tables 5 and 6).

In agreement with FPG data, SSA therapy, either alone or combined with PEG, was associated with a small, but significant, increase in $\mathrm{HbA1c}$ levels with respect to baseline; on the contrary, HbAlc levels were reduced, albeit slightly, after the discontinuation of SSA therapy $(\Delta \mathrm{PEG}-\mathrm{SSA}+\mathrm{PEG}=-0.37 \pm 0.07 ; P=0.0004)$.

As expected, fasting insulin levels were reduced during the medical therapy for acromegaly, mainly when disease control was achieved (Tables 4 and 5). In patients with uncontrolled disease under SSA therapy, inclusion of PEG was associated with a further reduction in fasting insulin levels $(P=0.0253)$, which did not differ from those observed in patients with controlled acromegaly either under SSA therapy or under PEG therapy (Table 6).

HOMA2-IR was reduced mainly when disease control was achieved either with SSA therapy (Table 4) or with PEG therapy (Table 5). HOMA- $\beta$, suggesting a $\beta$-cell hyperactivation in active acromegaly, was reduced when disease was controlled, without a significant difference among the different therapies (SSA, SSA+ PEG, or PEG alone) (Table 6).

QUICK-I, evaluating insulin sensitivity, was reduced in patients with active acromegaly. Disease control with 
Table 4 Effects of SSA therapy on glucose metabolism according to the control of acromegaly. Values are expressed as mean \pm s.E.M.

\begin{tabular}{|c|c|c|c|c|c|c|c|}
\hline & \multicolumn{2}{|c|}{ SSA $_{\text {all }- \text { basal }}(n=50)$} & \multicolumn{2}{|c|}{$\mathbf{S S A}_{\text {contr }- \text { basal }}(n=19)$} & \multicolumn{2}{|c|}{ SSA $_{\text {un-contr }}-$ basal $(n=31)$} & \multirow{2}{*}{$\begin{array}{l}P \text { between } \\
\text { the groups }\end{array}$} \\
\hline & $\Delta$ Mean \pm S.E.M. & $P$ & $\Delta$ Mean \pm S.E.M. & $P$ & $\Delta$ Mean \pm S.E.M. & $P$ & \\
\hline $\mathrm{GH}(\mu \mathrm{g} / \mathrm{l})$ & $-8.38 \pm 2.30$ & 0.0008 & $-14.50 \pm 3.22$ & 0.0069 & $-3.43 \pm 2.89$ & 0.0015 & 0.0149 \\
\hline IGF1 index & $-1.29 \pm 0.22$ & $<0.0001$ & $-1.99 \pm 0.36$ & $<0.0001$ & $-0.73 \pm 0.21$ & 0.0024 & 0.0028 \\
\hline Fasting glucose (mg/dl) & $10.45 \pm 1.47$ & $<0.0001$ & $6.53 \pm 1.58$ & 0.0006 & $14.00 \pm 2.16$ & $<0.0001$ & 0.0093 \\
\hline Fasting insulin $(\mu \mathrm{U} / \mathrm{ml})$ & $-4.91 \pm 1.64$ & 0.0055 & $-6.37 \pm 2.62$ & 0.0293 & $-3.45 \pm 1.98$ & 0.1031 & 0.3831 \\
\hline $\mathrm{HbA} 1 \mathrm{c}(\%)$ & $0.23 \pm 0.08$ & 0.0107 & $0.11 \pm 0.11$ & 0.4248 & $0.31 \pm 0.09$ & 0.0067 & 0.2170 \\
\hline HOMA2-IR & $-0.57 \pm 0.20$ & 0.0076 & $-0.75 \pm 0.32$ & 0.0329 & $-0.39 \pm 0.24$ & 0.1292 & 0.3654 \\
\hline HOMA- $\beta$ (\%) & $-48.85 \pm 9.92$ & $<0.0001$ & $-51.29 \pm 16.23$ & 0.0069 & $-46.41 \pm 11.98$ & 0.0017 & 0.8109 \\
\hline Disposition index & $-10.79 \pm 5.18$ & 0.0461 & $-0.48 \pm 6.14$ & 0.9387 & $-21.11 \pm 7.63$ & 0.0152 & 0.0444 \\
\hline QUICK index & $0.014 \pm 0.006$ & 0.0340 & $0.030 \pm 0.007$ & 0.0004 & $-0.002 \pm 0.009$ & 0.8423 & 0.0091 \\
\hline $\begin{array}{l}\text { OGTT glucose at } \\
0 \mathrm{~min}(\mathrm{mg} / \mathrm{dl})\end{array}$ & $10.03 \pm 2.68$ & 0.0008 & $10.90 \pm 3.73$ & 0.0091 & $8.40 \pm 3.40$ & 0.0358 & 0.6663 \\
\hline $\begin{array}{l}\text { OGTT glucose at } \\
120 \mathrm{~min}(\mathrm{mg} / \mathrm{dl})\end{array}$ & $42.93 \pm 9.45$ & $<0.0001$ & $34.58 \pm 10.72$ & 0.0047 & $58.80 \pm 18.07$ & 0.0099 & 0.2296 \\
\hline $\begin{array}{l}\text { OGTT AUC }{ }_{\text {glu }} \\
(\mathrm{mg} / \mathrm{dl} \times 120 \mathrm{~min})\end{array}$ & $2090 \pm 641$ & 0.0029 & $2186.8 \pm 875.0$ & 0.0223 & $1905.0 \pm 891.3$ & 0.0613 & 0.8389 \\
\hline $\begin{array}{l}\text { OGTT AUC } \\
(\mu \mathrm{Un} / \mathrm{ml} \times 120 \mathrm{~min})\end{array}$ & $-4022 \pm 957$ & 0.0008 & $-4502.2 \pm 1323.1$ & 0.0067 & $-2964.1 \pm 983.5$ & 0.0394 & 0.4757 \\
\hline$A \cup C_{\text {ins }} / A \cup C_{\text {olu }}$ & $-0.24 \pm 0.04$ & $<0.0001$ & $-0.25 \pm 0.05$ & 0.0006 & $-0.22 \pm 0.07$ & 0.0293 & 0.7419 \\
\hline Matsuda index & $2.56 \pm 0.47$ & $<0.0001$ & $2.41 \pm 0.40$ & 0.0001 & $2.89 \pm 1.30$ & 0.0906 & 0.6458 \\
\hline Insulinogenic index & $-0.53 \pm 0.11$ & 0.0002 & $-0.49 \pm 0.14$ & 0.0046 & $-0.60 \pm 0.20$ & 0.0395 & 0.6646 \\
\hline
\end{tabular}

Delta $(\Delta)$, the variation between the parameter observed in the second group and that observed in the first group; IGF1 index, the ratio of the measured IGF1 value to the upper limit for age; $A U C_{\text {glu }}$, area under the OGTT curve for glucose; $A U C_{\text {ins }}$, area under the OGTT curve for insulin; $A U C_{\text {ins }} / A U C_{\text {glu }}$, the ratio between the two AUC. $P$ between the groups refers to comparison between $\Delta$ values of the patients with controlled and uncontrolled disease under SSA therapy.

therapy with SSAs, SSA + PEG, or PEG was associated with a small, but significant, increase in the QUICK-I (Tables 4 and 5), without differences among the treatment groups (Table 6).

DI, a qualitative measurement that describes the relationship between $\beta$-cell function and insulin sensitivity, decreased during SSA therapy, particularly in patients with uncontrolled disease (Table 4, $\Delta \mathrm{SSA}_{\text {contr }}$ - basal vs $\Delta \mathrm{SSA}_{\text {un-contr }}$-basal; $\left.P<0.05\right)$. The DI increased when acromegaly was controlled by inclusion of PEG into SSA therapy in patients with uncontrolled disease (Table 5); however, therapy with

Table 5 Changes of glucose metabolism during different therapies for acromegaly. Values are expressed as Mean \pm S.E.M.

\begin{tabular}{|c|c|c|c|c|c|c|}
\hline & \multicolumn{2}{|c|}{$(\mathrm{SSA}+\mathrm{PEG})-\left(\mathrm{SSA}_{\text {un-contr }}\right)(n=31)$} & \multicolumn{2}{|c|}{$(\mathrm{PEG})-(\mathrm{SSA}+\mathrm{PEG})(n=18)$} & \multicolumn{2}{|c|}{$(\mathrm{PEG})-\left(\mathrm{SSA}_{\text {un-contr }}\right)(n=18)$} \\
\hline & $\Delta$ Mean \pm S.E.M. & $P$ & $\Delta$ Mean \pm S.E.M. & $P$ & $\Delta$ Mean \pm S.E.M. & $P$ \\
\hline $\mathrm{GH}(\mu \mathrm{g} / \mathrm{l})$ & $42.30 \pm 7.18$ & $<0.0001$ & $-5.28 \pm 4.30$ & 0.2433 & $27.87 \pm 7.88$ & 0.0041 \\
\hline IGF1 index & $-1.26 \pm 0.15$ & $<0.0001$ & $0.16 \pm 0.15$ & 0.3058 & $-1.36 \pm 0.21$ & $<0.0001$ \\
\hline Fasting glucose (mg/dl) & $-7.85 \pm 1.78$ & 0.0003 & $-9.86 \pm 3.56$ & 0.0161 & $-18.07 \pm 3.29$ & 0.0001 \\
\hline Fasting insulin $(\mu \mathrm{lU} / \mathrm{ml})$ & $-3.61 \pm 1.39$ & 0.0253 & $-1.75 \pm 0.88$ & 0.0733 & $-9.87 \pm 5.30$ & 0.0920 \\
\hline $\mathrm{HbA} 1 \mathrm{c}(\%)$ & $-0.24 \pm 0.06$ & 0.0005 & $-0.37 \pm 0.07$ & 0.0004 & $-0.40 \pm 0.11$ & 0.0060 \\
\hline HOMA2-IR & $-0.48 \pm 0.17$ & 0.0169 & $-0.22 \pm 0.13$ & 0.0645 & $-1.25 \pm 0.63$ & 0.745 \\
\hline HOMA- $\beta$ (\%) & $-12.28 \pm 8.89$ & 0.1946 & $6.77 \pm 4.57$ & 0.1671 & $-19.59 \pm 19.89$ & 0.3480 \\
\hline Disposition index & $22.28 \pm 6.62$ & 0.0063 & $59.28 \pm 24.95$ & 0.0367 & $83.42 \pm 21.71$ & 0.0033 \\
\hline QUICK index & $0.023 \pm 0.005$ & 0.0017 & $0.025 \pm 0.010$ & 0.0280 & $0.055 \pm 0.014$ & 0.0027 \\
\hline $\begin{array}{l}\text { OGTT glucose at } \\
0 \mathrm{~min}(\mathrm{mg} / \mathrm{dl})\end{array}$ & $-5.11 \pm 4.96$ & 0.3326 & $-7.00 \pm 3.22$ & 0.0522 & $-15.50 \pm 3.27$ & 0.0021 \\
\hline $\begin{array}{l}\text { OGTT glucose at } \\
120 \mathrm{~min}(\mathrm{mg} / \mathrm{dl})\end{array}$ & $-27.22 \pm 20.05$ & 0.2117 & $-23.83 \pm 12.74$ & 0.0441 & $-32.63 \pm 23.37$ & 0.2054 \\
\hline $\begin{array}{l}\text { OGTT AUC }{ }_{\text {glu }} \\
(\mathrm{mg} / \mathrm{dl} \times 120 \mathrm{~min})\end{array}$ & $-308.3 \pm 1705.5$ & 0.8610 & $-2612.5 \pm 991.3$ & 0.0232 & $-3684.4 \pm 780.7$ & 0.0022 \\
\hline $\begin{array}{l}\text { OGTT AUC }_{\text {ins }} \\
(\mu \mathrm{U} / \mathrm{ml} \times 120 \mathrm{~min})\end{array}$ & $-365.8 \pm 568.3$ & 0.5482 & $775.4 \pm 764.4$ & 0.3344 & $207.5 \pm 829.6$ & 0.8124 \\
\hline$A \cup C_{\text {ins }} / A \cup C_{\text {glu }}$ & $-0.003 \pm 0.035$ & 0.9248 & $0.08 \pm 0.04$ & 0.0614 & $0.06 \pm 0.05$ & 0.2614 \\
\hline Matsuda index & $1.86 \pm 0.89$ & 0.0893 & $0.04 \pm 0.74$ & 0.9566 & $1.42 \pm 1.07$ & 0.2403 \\
\hline Insulinogenic index & $0.01 \pm 0.13$ & 0.9477 & $0.38 \pm 0.12$ & 0.0119 & $0.31 \pm 0.14$ & 0.0817 \\
\hline
\end{tabular}

Delta $(\Delta)$, the variation between the parameter observed in the second group and that observed in the first group; IGF1 index, the ratio of the measured IGF1 value to the upper limit for age; $A \cup C_{\text {glu }}$, area under the OGTT curve for glucose; $A U C_{\text {ins }}$, area under the OGTT curve for insulin; $A U C_{\text {ins }} / A U C_{\text {glu }}$, the ratio between the two AUC. 
Table 6 Comparison of different therapies on glucose metabolism in patients with controlled acromegaly. Values are expressed as Mean \pm S.E.M.

\begin{tabular}{|c|c|c|c|c|c|c|}
\hline & \multicolumn{3}{|c|}{ Mean \pm s.E.M. } & \multicolumn{3}{|c|}{$P$} \\
\hline & $\begin{array}{c}\Delta\left(\mathrm{SSA}_{\text {contr }}\right)- \\
\quad \text { (basal) }\end{array}$ & $\begin{array}{c}\Delta(\mathrm{SSA}+\mathrm{PEG})- \\
\quad \text { (basal) }\end{array}$ & $\begin{array}{c}\Delta(\mathrm{PEG})- \\
\quad(\text { basal })\end{array}$ & $\begin{array}{c}\Delta{\left(\mathrm{SSA}_{\text {contr }}-\right.} \\
\text { basal) vs } \Delta \\
(\mathrm{SSA}+\mathrm{PEG}- \\
\text { basal) }\end{array}$ & $\begin{array}{c}\Delta\left(\mathrm{SSA}_{\text {contr }}-\right. \\
\text { basal) vs } \Delta \\
(\mathrm{PEG}-\text { basal) }\end{array}$ & $\begin{array}{c}\Delta(\mathrm{SSA}+\mathrm{PEG}- \\
\text { basal) vs } \Delta \\
(\mathrm{PEG}-\text { basal })\end{array}$ \\
\hline $\mathrm{GH}(\mu \mathrm{g} / \mathrm{l})$ & $-14.50 \pm 6.48$ & $31.25 \pm 6.68$ & $23.38 \pm 8.36$ & $<0.0001$ & 0.0003 & 0.4660 \\
\hline IGF1 index & $-1.99 \pm 0.33$ & $-2.11 \pm 0.23$ & $-1.69 \pm 0.30$ & 0.7620 & 0.5277 & 0.2611 \\
\hline Fasting glucose $(\mathrm{mg} / \mathrm{dl})$ & $6.53 \pm 2.21$ & $6.19 \pm 2.08$ & $-5.06 \pm 2.58$ & 0.8985 & 0.0010 & 0.0015 \\
\hline Fasting insulin $(\mu \mathrm{U} / \mathrm{ml})$ & $-6.37 \pm 4.01$ & $-6.64 \pm 3.47$ & $-12.82 \pm 4.04$ & 0.9392 & 0.2731 & 0.2547 \\
\hline $\mathrm{HbA} 1 \mathrm{c}(\%)$ & $0.11 \pm 0.10$ & $0.08 \pm 0.10$ & $-0.19 \pm 0.12$ & 0.8565 & 0.0575 & 0.1093 \\
\hline HOMA2-IR & $-0.75 \pm 0.47$ & $-0.81 \pm 0.41$ & $-1.56 \pm 0.47$ & 0.8954 & 0.2434 & 0.2374 \\
\hline HOMA- $\beta$ (\%) & $-51.29 \pm 22.71$ & $-52.76 \pm 19.04$ & $-69.02 \pm 22.18$ & 0.9439 & 0.5918 & 0.5820 \\
\hline Disposition index & $-0.48 \pm 14.10$ & $-4.09 \pm 11.95$ & $64.42 \pm 13.92$ & 0.6746 & 0.0035 & 0.0008 \\
\hline QUICK index & $0.030 \pm 0.010$ & $0.017 \pm 0.010$ & $0.052 \pm 0.011$ & 0.2150 & 0.1465 & 0.0222 \\
\hline $\begin{array}{l}\text { OGTT glucose at } \\
0 \mathrm{~min}(\mathrm{mg} / \mathrm{dl})\end{array}$ & $10.90 \pm 3.33$ & $7.92 \pm 2.40$ & $-4.13 \pm 2.94$ & 0.4861 & 0.0045 & 0.0030 \\
\hline $\begin{array}{l}\text { OGTT glucose at } \\
120 \mathrm{~min}(\mathrm{mg} / \mathrm{dl})\end{array}$ & $34.58 \pm 9.94$ & $41.38 \pm 10.32$ & $10.75 \pm 12.64$ & 0.6765 & 0.1147 & 0.0682 \\
\hline $\begin{array}{l}\text { OGTT AUC }{ }_{\text {glu }} \\
(\mathrm{mg} / \mathrm{dl} \times 120 \mathrm{~min})\end{array}$ & $2187 \pm 789$ & $2472 \pm 749$ & $-964 \pm 917$ & 0.8160 & 0.0109 & 0.0061 \\
\hline $\begin{array}{l}\text { OGTT AUC }_{\text {ins }} \\
(\mu \mathrm{U} / \mathrm{ml} \times 120 \mathrm{~min})\end{array}$ & $-4502 \pm 1190$ & $-6947 \pm 1343$ & $-4815 \pm 1645$ & 0.2229 & 0.8887 & 0.3239 \\
\hline$A \cup C_{\text {ins }} / A \cup C_{\text {glu }}$ & $-0.248 \pm 0.090$ & $-0.436 \pm 0.082$ & $-0.297 \pm 0.101$ & 0.0918 & 0.6988 & 0.2966 \\
\hline Matsuda index & $2.41 \pm 0.76$ & $3.34 \pm 0.77$ & $3.65 \pm 0.94$ & 0.3786 & 0.2481 & 0.7982 \\
\hline Insulinogenic index & $-0.49 \pm 0.26$ & $-0.90 \pm 0.30$ & $-0.18 \pm 0.37$ & 0.3458 & 0.4086 & 0.1419 \\
\hline
\end{tabular}

Delta $(\Delta)$, the variation between the parameter observed during therapy and that observed at baseline; IGF1 index, the ratio of the measured IGF1 value to the upper limit for age; $A \cup C_{\text {glu }}$, area under the OGTT curve for glucose; $A \cup C_{\text {ins }}$, area under the OGTT curve for insulin; $A \cup C_{\text {ins }} / A \cup C_{\text {glu }}$, the ratio between the two AUC.

PEG alone was associated with higher values of the DI than therapy with SSA+PEG or SSAs alone (Table 6, $P=0.0008$ and $P=0.0035$ respectively).

\section{Effects of medical therapies on glucose metabolism evaluated during the OGTT}

Therapy with SSAs was associated with an increase in glucose levels during the OGTT at baseline (time $0 \mathrm{~min}$ ) and after $120 \mathrm{~min}$ as well as during all the measured time points $\left(\mathrm{AUC}_{\mathrm{glu}}\right)$, without differences among the patients with controlled or uncontrolled disease (Table 4). The inclusion of PEG into SSA therapy in subjects with uncontrolled disease was associated with an improvement in glucose parameters, which, however, reached statistical significance only when SSA therapy was withdrawn and PEG therapy alone was continued (Table 5 and Fig. 2A).

Patients treated with SSAs or SSA + PEG, at variance with those receiving PEG therapy alone, had a low insulin response during the early phase of the OGTT, as suggested by the different shapes of the insulin curve (Fig. 2B) and the insulinogenic index (Tables 4 and 5).

\section{Prevalence of abnormalities of glucose metabolism during different therapies for acromegaly}

The prevalence of glucose abnormalities differed during medical therapies for acromegaly (Table 7). Overall, DM was more frequent during SSA therapy than at baseline or during PEG therapy (Table 7); on the contrary, the proportion of normal glucose tolerance was higher, albeit not significant, in patients receiving PEG therapy than in those receiving SSA therapy (Table 7).

\section{Discussion}

The results of this study show that medical therapies for acromegaly differently affect glucose homeostasis. Overall, treatment with PEG seems to be associated with an improved glycometabolic profile with respect to the diagnosis of acromegaly or to the therapy with SSAs. On the contrary, in our series, SSA therapy was associated with detrimental effects on glucose homeostasis both in patients with uncontrolled disease and in patients with controlled disease.

Our results extend data from previous studies $(11,15$, $16,17,18,19,20,21)$, suggesting that PEG may have beneficial effects on glucose metabolism besides disease control.

The high prevalence of insulin resistance and glucose metabolism abnormalities has been considered a risk factor for the increased morbidity and mortality observed in patients with acromegaly $(2,3,14)$. In fact, $\mathrm{GH}$ increases glucose production through various mechanisms, including stimulation of lypolysis and inhibition of insulin-mediated suppression of hepatic gluconeogenesis $(1,6)$. These abnormalities are 

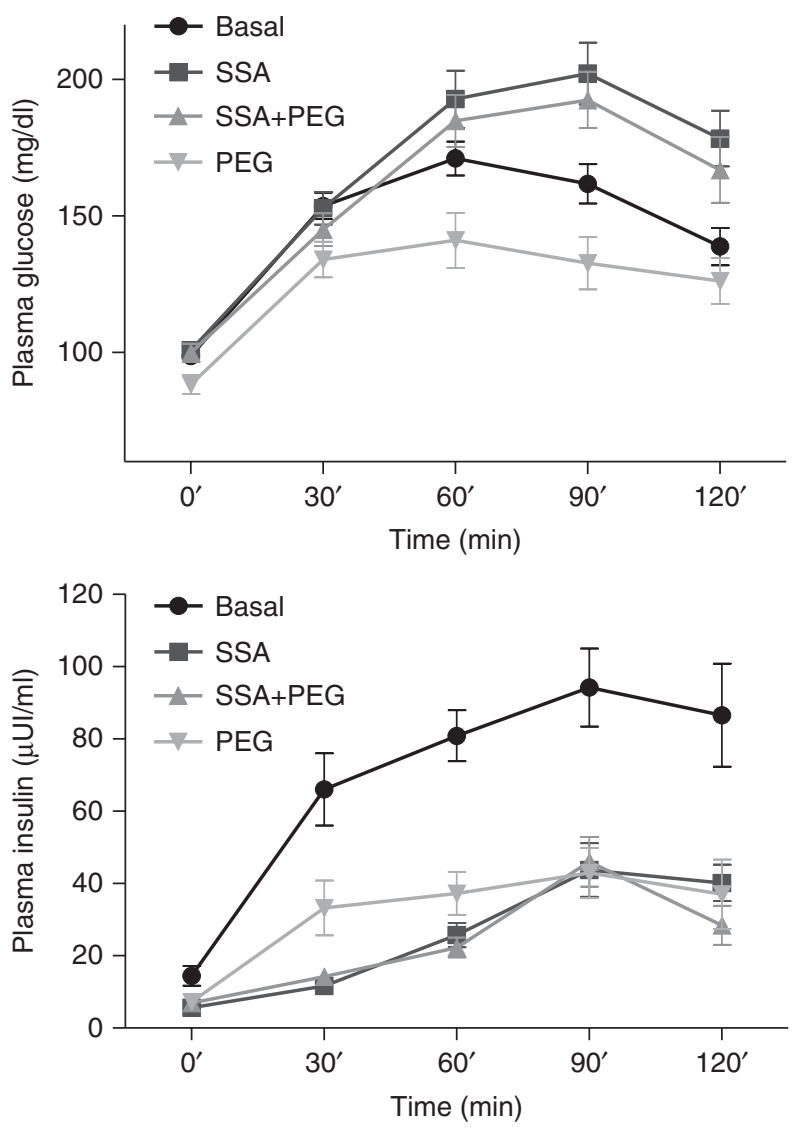

Figure 2 Glucose and insulin response to the oral glucose tolerance test (OGTT). OGTT was performed as detailed in Materials and methods. Differences in the mean value ( \pm S.E.M.) of insulin and glucose concentrations during different therapies for acromegaly were evaluated by ANOVA. Basal, untreated patients with active acromegaly; SSA, patients under somatostatin analog (SSA) therapy; SSA + pegvisomant (PEG), patients under the combined (SSA + PEG) therapy; PEG, patients under PEG therapy alone.

responsible for the GH-dependent increase in insulin resistance and for the decrease in insulin sensitivity (19).

SSA therapy is effective for treating acromegaly, allowing the control of $\mathrm{GH}$ hypersecretion and limiting the impact of systemic complications of the disease in a subset of patients (34). Several studies have investigated the effects of therapy with SSAs on glucose metabolism of acromegalic patients, raising concerns about the potential negative effects on $\beta$-cell function $(5,9,10$, $11,12,13,14)$. In fact, although a recent metaanalysis has indicated that, overall, SSA therapy has no detrimental glycometabolic effects, the results of single studies are rather divergent, suggesting that, at least in a subset of patients, SSA therapy may negatively affect glucose metabolism (14).

The effects of the administration of PEG on glucose metabolism are not completely understood, although some studies have suggested a beneficial effect on glucose tolerance and insulin sensitivity $(11,15,16$, $17,18,19,20,21,35,36)$. In particular, previous pilot studies (one performed in normal volunteers and the other in small cohorts of patients) have reported that PEG therapy may either have a neutral effect or have a positive effect on glucose homeostasis $(11,18,19,20)$ and insulin sensitivity $(11,18,19,21)$. A multicenter study, performed in a larger cohort of acromegalic subjects, has confirmed that a change from SSA therapy to PEG therapy can improve glucose homeostasis regardless of the control of acromegaly (16). Other studies have evaluated the impact of the inclusion of PEG in a small group of acromegalic patients treated with SSAs, demonstrating only minor effects on glucose homeostasis and insulin sensitivity $(17,35,36)$.

In the present study, independently of the type of medical therapy, biochemical control of acromegaly was associated with an improved insulin resistance, reduced serum insulin levels, and a reduction of compensatory increase in $\beta$-cell function compared with the untreated disease.

However, our data suggest that SSA and PEG therapies have different effects on glucose metabolism. In fact, improvement of insulin homeostasis (i.e. a more pronounced increase in insulin sensitivity and a concomitant reduction in insulin resistance) was higher in patients with controlled acromegaly with PEG than in those with controlled disease with SSAs in comparison with the baseline values. This observation confirmed previous studies, performed in subjects in whom a change from SSA therapy to PEG therapy was made, suggesting that the two drugs had different effects on insulin homeostasis $(11,16,18)$.

In addition, we observed that the DI, a parameter linking $\beta$-cell function and insulin sensitivity, was higher in acromegalic patients with controlled disease during PEG therapy than in those controlled with SSAs, suggesting that PEG was associated with a better profile of the insulin-dependent components of glucose tolerance. Epidemiological studies suggest that a reduced DI

Table 7 Proportion of abnormalities of glucose metabolism during different medical therapies for acromegaly. The data are expressed as numer and percentage of total.

\begin{tabular}{lcrrr}
\hline & NGT & $\begin{array}{c}\text { IFG and/ } \\
\text { or IGT }\end{array}$ & DM & $\boldsymbol{P}$ \\
\hline$n=50$ & & & & \\
Basal & $20(40.0)$ & $25(50.0)$ & $5(10.0)$ & $<0.0001$ \\
SSA $_{\text {all }}$ & $2(4.0)$ & $25(50.0)$ & $23(46.0)$ & \\
$n=19$ & & & & \\
Basal & $4(21.0)$ & $14(73.7)$ & $1(5.3)$ & 0.0293 \\
SSA $_{\text {contr }}$ & $2(10.5)$ & $9(47.4)$ & $8(42.1)$ & \\
$n=31$ & & & & \\
Basal $_{\text {SSA }}$ & $16(51.6)$ & $11(35.5)$ & $4(12.9)$ & 0.0001 \\
$n=31$ & $0(0.0)$ & $16(51.6)$ & $15(48.4)$ & \\
SSA & & & & \\
SSA+PEG & & & & \\
$n=18$ & $3(9.0)$ & $16(51.6)$ & $15(48.4)$ & 0.2322 \\
SSA+PEG & $3(16.7)$ & $11(61.6)$ & $12(38.7)$ & \\
PEG & $8(44.4)$ & $9(50.0)$ & $4(22.2)$ & 0.0719 \\
\hline
\end{tabular}

NGT, normal glucose tolerance; IFG, impaired fasting glucose; IGT, impaired glucose tolerance; DM, diabetes mellitus. 
may be a risk factor for the development of diabetes, in addition to family history, age, sex, ethnicity, and obesity (37). However, whether changes in the DI associated with SSA or PEG therapy affect the incidence of DM in acromegalic patients remains to be addressed.

Our data are in agreement with previous reports, showing that SSA therapy may influence glucose metabolism in acromegaly both indirectly, by reducing GH and IGF1 levels, and directly, by reducing insulin secretion $(5,9,10)$. On the contrary, PEG therapy might indirectly improve insulin sensitivity and reduce insulin resistance through a selective removal of the inhibitory effect of GH on insulin action $(16,18)$. This is in agreement with data obtained in knockout animals for the $\mathrm{GH}$ receptor. In fact, these animals, which can be considered a model that is similar to subjects treated with PEG, are characterized by an increase in insulin sensitivity and seem to be more resistant to the streptozotocin-induced development of glucose intolerance (38).

In addition, in our study, SSA therapy was associated with a small, but significant, increase in FPG and HbA1c levels, whereas during PEG therapy, FPG and HbA1c concentrations were reduced.

On clinical grounds, the prevalence of glucose tolerance abnormalities (IGT, IFG, or overt DM) in subjects with controlled acromegaly during SSA therapy was higher than that in those controlled with PEG, whereas the opposite occurred for the prevalence of normal glucose tolerance.

The present study has some limitations; the first of which is its retrospective nature and the fact that time elapsed during each treatment period differed; however, it is worth noting that all patients shared the same diagnostic protocol, which included the same evaluation of glucose metabolism, performed on a prospective basis, thus limiting the different evaluation periods. An additional limitation of the study is that the indirect indexes used to evaluate insulin homeostasis (insulin sensitivity and resistance as well as $\beta$-cell activation) have been validated for the general population and so might not adequately fit for acromegalic patients, in whom several parameters may influence glycemic control (e.g. adrenergic tone and cortisol and incretin levels) in addition to GH and IGF1 levels. However, because of the retrospective nature of the study, a direct measurement of insulin resistance, performed by the euglycemic clamp method, was not available in our population.

In conclusion, medical therapies for acromegaly with SSAs or PEG differently affect glucose metabolism. The control of acromegaly activity with each medical therapy is associated with an improvement in insulin homeostasis. However, SSA therapy seems to be associated with small but significant detrimental effects on glucose indexes, which on the contrary seem to be ameliorated during PEG therapy.

\section{Declaration of interest}

The authors declare that there is no conflict of interest that could be perceived as prejudicing the impartiality of the research reported.

\section{Funding}

This work was partially supported by grants from the University of Pisa (Fondi d'Ateneo) to F Bogazzi and E Martino.

\section{Author contribution statement}

All authors had access to all the study data, analyzed the data, interpreted the data, and reviewed, edited, and approved the report for publication. C Urbani, F Bogazzi, and E Martino designed the study. G Rossi undertook the statistical analysis.

\section{Acknowledgements}

We thank Prof. Piero Marchetti (at the University of Pisa) for careful reading of the manuscript and the Peretti Foundation (Rome, Italy) for logistic support.

\section{References}

1 LeRoith D \& Yakar S. Mechanisms of disease: metabolic effects of growth hormone and insulin-like growth factor 1. Nature Clinical Practice. Endocrinology \& Metabolism 20073 302-310. (doi:10.1038/ncpendmet0427)

2 Colao A, Ferone D, Marzullo P \& Lombardi G. Systemic complications of acromegaly: epidemiology, pathogenesis, and management. Endocrine Reviews $2004 \quad 25$ 102-152. (doi:10.1210/er.2002-0022)

3 Ben-Shlomo A \& Melmed S. Acromegaly. Endocrinology and Metabolism Clinics of North America 200837 101-122, viii. (doi:10.1016/j.ecl.2007.10.002)

4 Sonksen PH, Greenwood FC, Ellis JP, Lowy C, Rutherford A \& Nabarro JD. Changes of carbohydrate tolerance in acromegaly with progress of the disease and in response to treatment. Journal of Clinical Endocrinology and Metabolism $1967 \quad 27 \quad 1418-1430$. (doi:10.1210/jcem-27-10-1418)

5 Wass JA, Cudworth AG, Bottazzo GF, Woodrow JC \& Besser GM. An assessment of glucose intolerance in acromegaly and its response to medical treatment. Clinical Endocrinology 198012 53-59. (doi:10.1111/j.1365-2265.1980.tb03132.x)

6 Moller N \& Jorgensen JO. Effects of growth hormone on glucose, lipid, and protein metabolism in human subjects. Endocrine Reviews 200930 152-177. (doi:10.1210/er.2008-0027)

7 Hansen I, Tsalikian E, Beaufrere B, Gerich J, Haymond M \& Rizza R. Insulin resistance in acromegaly: defects in both hepatic and extrahepatic insulin action. American Journal of Physiology 1986 250 E269-E273.

8 Colao A, Martino E, Cappabianca P, Cozzi R, Scanarini M \& Ghigo E. First-line therapy of acromegaly: a statement of the A.L.I.C.E. (Acromegaly primary medical treatment Learning and Improvement with Continuous Medical Education) Study Group. Journal of Endocrinological Investigation 200629 1017-1020.

9 Alberti KG, Christensen NJ, Christensen SE, Hansen AP, Iversen J, Lundbaek K, Seyer-Hansen K \& Orskov H. Inhibition of insulin secretion by somatostatin. Lancet 19732 1299-1301. (doi:10.1016/S0140-6736(73)92873-0)

10 Koop BL, Harris AG \& Ezzat S. Effect of octreotide on glucose tolerance in acromegaly. European Journal of Endocrinology 1994 130 581-586. (doi:10.1530/eje.0.1300581)

11 Parkinson C, Drake WM, Roberts ME, Meeran K, Besser GM \& Trainer PJ. A comparison of the effects of pegvisomant and octreotide on glucose, insulin, gastrin, cholecystokinin, and 
pancreatic polypeptide responses to oral glucose and a standard mixed meal. Journal of Clinical Endocrinology and Metabolism 2002 87 1797-1804. (doi:10.1210/jc.87.4.1797)

12 Baldelli R, Battista C, Leonetti F, Ghiggi MR, Ribaudo MC, Paoloni A, D’Amico E, Ferretti E, Baratta R, Liuzzi A et al. Glucose homeostasis in acromegaly: effects of long-acting somatostatin analogues treatment. Clinical Endocrinology $2003 \mathbf{5 9} 492-499$. (doi:10.1046/j.1365-2265.2003.01876.x)

13 Ronchi C, Epaminonda P, Cappiello V, Beck-Peccoz P \& Arosio M. Effects of two different somatostatin analogs on glucose tolerance in acromegaly. Journal of Endocrinological Investigation $2002 \mathbf{2 5}$ 502-507.

14 Mazziotti G, Floriani I, Bonadonna S, Torri V, Chanson P \& Giustina A. Effects of somatostatin analogs on glucose homeostasis: a metaanalysis of acromegaly studies. Journal of Clinical Endocrinology and Metabolism 200994 1500-1508. (doi:10.1210/jc.2008-2332)

15 van der Lely AJ, Hutson RK, Trainer PJ, Besser GM, Barkan AL, Katznelson L, Klibanski A, Herman-Bonert V, Melmed S, Vance ML et al. Long-term treatment of acromegaly with pegvisomant, a growth hormone receptor antagonist. Lancet $2001 \mathbf{3 5 8}$ 1754-1759. (doi:10.1016/S0140-6736(01)06844-1)

16 Barkan AL, Burman P, Clemmons DR, Drake WM, Gagel RF, Harris PE, Trainer PJ, van der Lely AJ \& Vance ML. Glucose homeostasis and safety in patients with acromegaly converted from long-acting octreotide to pegvisomant. Journal of Clinical Endocrinology and Metabolism 200590 5684-5691. (doi:10.1210/ jc.2005-0331)

17 Jorgensen JO, Feldt-Rasmussen U, Frystyk J, Chen JW, Kristensen LO, Hagen C \& Orskov H. Cotreatment of acromegaly with a somatostatin analog and a growth hormone receptor antagonist. Journal of Clinical Endocrinology and Metabolism 2005 90 5627-5631. (doi:10.1210/jc.2005-0531)

18 Drake WM, Rowles SV, Roberts ME, Fode FK, Besser GM, Monson JP \& Trainer PJ. Insulin sensitivity and glucose tolerance improve in patients with acromegaly converted from depot octreotide to pegvisomant. European Journal of Endocrinology 2003149 521-527. (doi:10.1530/eje.0.1490521)

19 Rose DR \& Clemmons DR. Growth hormone receptor antagonist improves insulin resistance in acromegaly. Growth Hormone $\mathcal{E}$ IGF Research 200212 418-424. (doi:10.1016/S1096-6374(02) 00083-7)

20 Lindberg-Larsen R, Moller N, Schmitz O, Nielsen S, Andersen M, Orskov H \& Jorgensen JO. The impact of pegvisomant treatment on substrate metabolism and insulin sensitivity in patients with acromegaly. Journal of Clinical Endocrinology and Metabolism 2007 92 1724-1728. (doi:10.1210/jc.2006-2276)

21 Higham CE, Rowles S, Russell-Jones D, Umpleby AM \& Trainer PJ. Pegvisomant improves insulin sensitivity and reduces overnight free fatty acid concentrations in patients with acromegaly. Journal of Clinical Endocrinology and Metabolism $2009 \mathbf{9 4}$ 2459-2463. (doi:10.1210/jc.2008-2086)

22 Giustina A, Chanson P, Bronstein MD, Klibanski A, Lamberts S, Casanueva FF, Trainer P, Ghigo E, Ho K \& Melmed S. A consensus on criteria for cure of acromegaly. Journal of Clinical Endocrinology and Metabolism 201095 3141-3148. (doi:10.1210/jc.2009-2670)

23 Bogazzi F, Cosci C, Sardella C, Costa A, Manetti L, Gasperi M, Rossi G, Bartalena L \& Martino E. Identification of acromegalic patients at risk of developing colonic adenomas. Journal of Clinical Endocrinology and Metabolism 200691 1351-1356. (doi:10.1210/jc.2005-2500)

24 American Diabetes Association. Diagnosis and Classification of diabetes mellitus. Diabetes Care 201134 (Suppl 1) S62-S69. (doi:10.2337/dc11-S062)

25 Matthews DR, Hosker JP, Rudenski AS, Naylor BA, Treacher DF \& Turner RC. Homeostasis model assessment: insulin resistance and beta-cell function from fasting plasma glucose and insulin concentrations in man. Diabetologia 1985 28 412-419. (doi:10.1007/BF00280883)
26 Wallace TM, Levy JC \& Matthews DR. Use and abuse of HOMA modeling. Diabetes Care 200427 1487-1495. (doi:10.2337/ diacare.27.6.1487)

27 Matsuda M. Measuring and estimating insulin resistance in clinical and research settings. Nutrition, Metabolism, and Cardiovascular Diseases 201020 79-86. (doi:10.1016/j.numecd. 2009.07.007)

28 Katz A, Nambi SS, Mather K, Baron AD, Follmann DA, Sullivan G \& Quon MJ. Quantitative insulin sensitivity check index: a simple, accurate method for assessing insulin sensitivity in humans. Journal of Clinical Endocrinology and Metabolism $2000 \quad \mathbf{8 5}$ 2402-2410. (doi:10.1210/jc.85.7.2402)

29 Matsuda M \& DeFronzo RA. Insulin sensitivity indices obtained from oral glucose tolerance testing: comparison with the euglycemic insulin clamp. Diabetes Care 199922 1462-1470. (doi:10.2337/diacare.22.9.1462)

30 Tai MM. A mathematical model for the determination of total area under glucose tolerance and other metabolic curves. Diabetes Care 199417 152-154. (doi:10.2337/diacare.17.2.152)

31 Retnakaran R, Shen S, Hanley AJ, Vuksan V, Hamilton JK \& Zinman B. Hyperbolic relationship between insulin secretion and sensitivity on oral glucose tolerance test. Obesity 200816 1901-1907. (doi:10.1038/oby.2008.307)

32 Phillips DI, Clark PM, Hales CN \& Osmond C. Understanding oral glucose tolerance: comparison of glucose or insulin measurements during the oral glucose tolerance test with specific measurements of insulin resistance and insulin secretion. Diabetic Medicine 199411 286-292. (doi:10.1111/j.1464-5491.1994. tb00273.x)

33 Bogazzi F, Manetti L, Lombardi M, Giovannetti C, Raffaelli V, Urbani C, Scattina I, Pepe P, Iannelli A, Martino E et al. Impact of different cut-off limits of peak GH after GHRH-arginine stimulatory test, single IGF1 measurement, or their combination in identifying adult patients with GH deficiency. European Journal of Endocrinology 2011164 685-693. (doi:10.1530/EJE-10-1068)

34 Petersenn S, Buchfelder M, Reincke M, Strasburger CM, Franz H, Lohmann R, Quabbe HJ \& Plockinger U. Results of surgical and somatostatin analog therapies and their combination in acromegaly: a retrospective analysis of the German Acromegaly Register. European Journal of Endocrinology 2008159 525-532. (doi:10.1530/EJE-08-0498)

35 De Marinis L, Bianchi A, Fusco A, Cimino V, Mormando M, Tilaro L, Mazziotti G, Pontecorvi A \& Giustina A. Long-term effects of the combination of pegvisomant with somatostatin analogs (SSA) on glucose homeostasis in non-diabetic patients with active acromegaly partially resistant to SSA. Pituitary $2007 \mathbf{1 0}$ 227-232. (doi:10.1007/s11102-007-0037-7)

36 Madsen M, Poulsen PL, Orskov H, Moller N \& Jorgensen JO. Cotreatment with pegvisomant and a somatostatin analog (SA) in SA-responsive acromegalic patients. Journal of Clinical Endocrinology and Metabolism 201196 2405-2413. (doi:10.1210/ jc. 2011-0654)

37 Lorenzo C, Wagenknecht LE, Rewers MJ, Karter AJ, Bergman RN, Hanley AJ \& Haffner SM. Disposition index, glucose effectiveness, and conversion to type 2 diabetes: the Insulin Resistance Atherosclerosis Study (IRAS). Diabetes Care 201033 2098-2103. (doi:10.2337/ dc10-0165)

38 Chen NY, Chen WY, Bellush L, Yang CW, Striker LJ, Striker GE \& Kopchick JJ. Effects of streptozotocin treatment in growth hormone (GH) and GH antagonist transgenic mice. Endocrinology 1995136 660-667. (doi:10.1210/en.136.2.660)

Received 11 January 2013

Revised version received 30 April 2013

Accepted 9 May 2013 